\title{
Phacoemulsification in adult patients with post-uveitis complicated cataract
}

\author{
Macarie Sorin Simion*, Macarie Daniela Mariana** \\ *Department of Ophthalmology, "Iuliu Hatieganu" University of Medicine \\ and Pharmacy, Cluj-Napoca, Romania \\ **Department of Ophthalmology, Integrated Ambulatory, Clinical \\ Hospital of Infectious Diseases, Cluj-Napoca, Romania
}

Correspondence to: Sorin Macarie, $\mathrm{MD}, \mathrm{PhD}$,

Department of Ophthalmology, "Iuliu Hatieganu" University of Medicine and Pharmacy, Cluj-Napoca,

8 Victor Babes Street, Code 400012, Cluj-Napoca, Romania,

Mobile phone: +40722 499 041, E-mail: sorin_macarie@yahoo.com

Accepted: March 22nd, 2018

\begin{abstract}
Objective: To evaluate the difficulties, complications and outcome of cataract surgery in patients with complicated cataract after anterior uveitis.

Methods: A retrospective study on 37 patients who suffered phacoemulsification surgery for post-uveitis complicated cataract in the period 2009-2014 was performed. 43 eyes underwent surgery.

Results: Posterior synechiae were present in 25 eyes. Posterior synechiolysis ensured large pupil in 15 eyes, and, in 14 eyes, the use of iris hooks or pupil expansion ring was necessary for surgery. Posterior capsule rupture was reported in 1 eye. Opacified and thick posterior capsule was noticed in 6 eyes. After surgery, transient rising of intraocular pressure was noticed in 4 eyes and prolonged postoperative inflammation was present in 3 eyes. Posterior capsule opacification was the most frequent issue ( 9 eyes) and cystoid macular oedema was reported in 2 eyes.

Conclusions: Post-uveitis complicated cataract surgery presents specific difficulties and postoperative complications are present in these patients, like prolonged postoperative inflammation and cystoid macular oedema.
\end{abstract}

Keywords: cataract, phacoemulsification, anterior uveitis, postoperative complications

\section{Introduction}

Cataract surgery for post-uveitis cataract represents approximately $1,2 \%$ of all cataract surgery procedures in adults [1]. In most of those patients, eyes present some aspects that can produce either difficulties and complications during surgery, or short or long-term complications. Irregular and small pupil, anterior synechiae, atrophic iris, small anterior chamber, weak capsular bag, or zonulae are some of those aspects. Retinal disorders (macular oedema, retinal scars, vitreoretinal interface pathology) can preexist or can occur after cataract surgery. All those factors can determine poor visual outcome after cataract surgery in these patients.

\section{Methods}

A retrospective study on 37 patients, who underwent phacoemulsification (37 eyes) surgery during the period 2009-2014 for complicated cataract after endogen anterior 
uveitis, was performed. 21 patients were males (56,75\%), 16 females (43,25\%). Patients' age and sex distribution is represented in Fig. 1. Three patients presented ankylosing spondylitis, one patient presented psoriasis with arthritis, and the others idiopathic anterior uveitis. Phacoemulsification surgery was performed with 2,2 $\mathrm{mm}$ incision with Alcon Infiniti and Alcon Constellation systems. All the patients underwent surgery only if they presented a minimum period of 6 months of inactive inflammation.

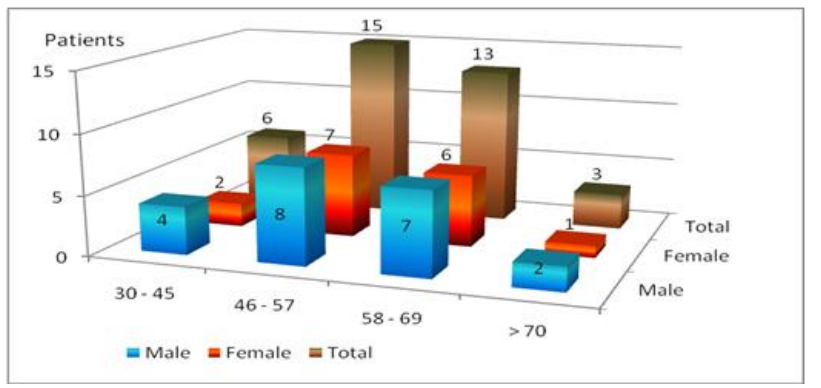

Fig. 1 Age and sex distribution of the patients included in our study

\section{Results}

16 patients (43.24\%) presented irregular pupil with 1-3 posterior synechiae, 9 patients (24.32\%) presented small pupil, with extended posterior synechiae $(24,32 \%)$ and 26 patients $(70,27 \%)$ presented pigment on the anterior capsule of the lens. All the patients presented normal intraocular pressure, 11 patients presented goniosynechiae $(29,7 \%)$. An accurate retinal examination was not possible in 8 patients and the other patients presented a normal retinal aspect.

The type and hardness of cataract is presented in Table 1.

Table 1. Type of cataract and nucleus hardness of the patients included in our study

\begin{tabular}{|c|c|c|c|c|}
\hline $\begin{array}{l}\text { Type of cataract } \\
\text { Nucleus hardness }\end{array}$ & $\begin{array}{l}\text { Posterior } \\
\text { subcapsular }\end{array}$ & Nuclear & $\begin{array}{l}\text { Cortical and } \\
\text { posterior } \\
\text { subcapsular }\end{array}$ & $\begin{array}{l}\text { Nuclear and } \\
\text { posterior } \\
\text { subcapsular } 70\end{array}$ \\
\hline+ & 7 & 0 & 5 & 0 \\
\hline++ & 2 & 3 & 2 & 3 \\
\hline+++ & 0 & 7 & 0 & 8 \\
\hline
\end{tabular}

Preoperative dilatation of the pupil was good in 12 patients $(32,43 \%)$. In 15 patients (37.83\%), synechiolysis with cystotome needle allowed us to obtain a good pupil diameter for phacoemulsification. In $10(27,02 \%)$ cases, we had to use iris hooks or perfect pupil rings from the beginning of the surgical procedure: in 4 patients, the pupil became small, despite good initial dilation, and we also had to use iris hooks. In 9 cases $(24,32 \%)$, we found a thin friable anterior capsule, and 5 patients presented diffuse iris atrophy. Opacified and thick posterior capsule was noticed in 6 eyes $(16,21 \%)$.

In 31 patients $(83,78 \%)$, we had no incidents during surgery. Two patients presented anterior capsule tear after synechiolysis, one patient presented a small anterior chamber bleeding after intraocular lens implantation, and, in two patients, we observed zonulolysis and we had to implant a capsular tensional ring. In one patient, we observed posterior capsule rupture and we had to perform anterior vitrectomy.

After surgery, transient rising of intraocular pressure was noticed in 4 eyes $(10,81 \%)$ more frequent than in non-uveitis patients, estimated at $0,5 \%$ [2]. Prolonged postoperative inflammation (more than 14 days) was present in 3 eyes. Posterior capsule opacification was the most frequent issue in the first 6 months after surgery (9 eyes - 24,32\%). Cystoid macular oedema was reported in 2 eyes $(5,4 \%)$ at 4 and 6 months after surgery, more frequent than in senile (non-uveitis) patients, being estimated at $4 \%$ [3]. One of the patients presented posterior capsule rupture during surgery; the other suffered Nd-YAG laser capsulotomy.

Preoperative and postoperative visual acuity is presented in Fig. 2. 24 patients $(64,86 \%)$ presented visual acuity better than 0,8 
at 1 month after surgery, and $27(72,9 \%)$ at one year.

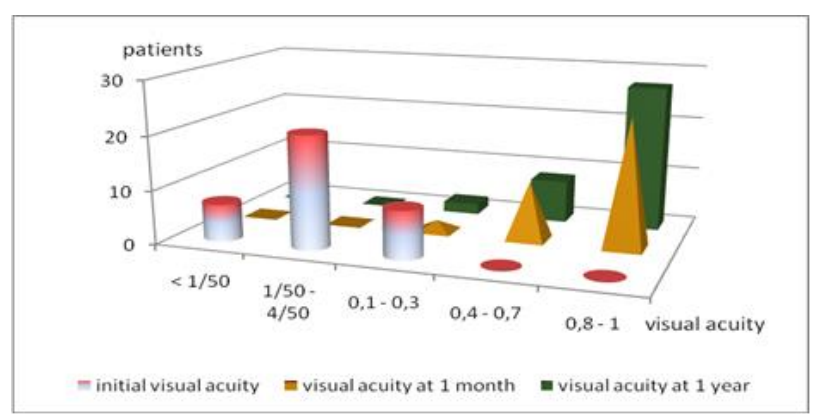

Fig. 2 Preoperative and postoperative visual acuity

\section{Discussions}

Cataract is a common complication of uveitis $[3,4]$. Surgical management of complicated cataract after anterior uveitis needs additional actions, especially for achieving and maintaining a good mydriasis [4] or for a good stabilization of the intraocular lens. Posterior capsule opacification is the most frequent issue in these patients $[2,5]$. Cystoid macular edema occurs after surgery in the patients who suffered posterior capsule rupture (accidentally or by $\mathrm{Nd}$ YAG laser capsulotomy); some authors state that perioperative systemic therapy is protective against those complications [6,7]. Prolonged eye inflammation after surgery is relatively rare, especially if heparin-surface-modified intraocular lenses are implanted [8]. Postoperative rising of intraocular pressure can occur frequently in these patients [2,9]. Good preoperative and postoperative control of inflammation plays an important role in achieving favorable visual outcomes $[\mathbf{9 , 1 0}]$. Visual outcome is generally good, but poorer than in non-uveitis eyes [11].

\section{Conclusions}

Surgery of complicated cataract after anterior uveitis offers good visual outcome in $72,9 \%$ of the cases (visual acuity of more than 0.8 ). Iris hooks or perfect pupil rings are very frequently required in these patients $(37,83 \%)$. Posterior capsule opacification and cystoid macular edema are more frequent than in senile (non-uveitis) cataract. After surgery, elevated intraocular pressure and prolonged ocular inflammation can occur.

\section{Disclosures}

None

\section{References}

1. Shu-Wen Chan N, Ti SE, Chee SP. Decision-making and management of uveitic cataract. Indian J Ophthalmol. 2017 Dec; 65(12):1329-1339.

2. Pålsson S, Andersson Grönlund M, Skiljic D, Zetterberg M. Phacoemulsification with primary implantation of an intraocular lens in patients with uveitis. Clin Ophthalmol. 2017 Aug 22; 11:1549-155.

3. Jones NP. The Manchester Uveitis Clinic: The first 3000 patients, 2: Uveitis Manifestations, Complications, Medical, and Surgical Management. Ocul Immunol Inflamm. 2015 Apr; 23(2):127-34.

4. Chu CJ, Dick AD, Johnston RL, Yang YC, Denniston AK. Cataract surgery in uveitis: a multicentre database study. Br J Ophthalmol. 2017 Aug; 101(8):1132-1137.

5. Chiu H, Dang H, Cheung C, Khosla D, Arjmand P, Rabinovitch T, Derzko-Dzulynsky L. Ten-year retrospective review of outcomes following phacoemulsification with intraocular lens implantation in patients with pre-existing uveitis. Can J Ophthalmol. 2017 Apr; 52(2):175-180.

6. Belair ML, Kim SJ, Thorne JE, Dunn JP, Kedhar SR, Brown DM, Jabs DA. Incidence of Cystoid Macular Edema after Cataract Surgery in Patients with and without Uveitis Using Optical Coherence Tomography. Am J Ophthalmol. 2009 Jul; 148(1):128-35.

7. Elgohary MA, McCluskey PJ, Towler HMA, Okhravi N, Singh RP, Obikpo R, Lightman SS. Outcome of phacoemulsification in patients with uveitis. $\mathrm{Br} \mathrm{J}$ Ophthalmol. 2007 Jul; 91(7):916-21.

8. Zhang Y, Zhu X, He W, Jiang Y, Lu Y. Efficacy of cataract surgery in patients with uveitis. Medicine (Baltimore). 2017 Jul; 96(30).

9. Cerqueira PMG, Silva FTBGCD, Carricondo PC, Olivalves E, Hirata CE, Yamamoto JH. Outcomes of phacoemulsification in patients with uveitis at a tertiary center in São Paulo, Brazil: a review of cases from 2007 to 2012. Arq Bras Oftalmol. 2017 Mar-Apr; 80(2):104-107.

10. Sen HN, Abreu FM, Louis TA, Sugar EA, Altaweel MM, Elner SG, Holbrook JT, Jabs DA, Kim RY, Kempen JH. Cataract Surgery Outcomes in Uveitis: The Multicenter Uveitis Steroid Treatment Trial. Ophthalmology. 2016 Jan; 123(1):183-90.

11. Chu CJ, Dick AD, Johnston RL, Yang YC, Denniston AK. Cataract surgery in uveitis: a multicentre database study. Br J Ophthalmol. 2017 Aug; 101(8):1132-1137. 